\section{AB0759 THE ASSESSMENT OF GASTROINTESTINAL TRACT INVOLVEMENT THROUGH UCLA SCTC GIT 2.0 QUESTIONNAIRE IDENTIFIES SCLERODERMA PATIENTS WITH REDUCED BONE MINERAL DENSITY}

G. Natalello, E. De Lorenzis, G.B. Canestrari, L. Gigante, L. Verardi, L. Mirone, S. L. Bosello, G. Ferraccioli, E. Gremese. Rheumatology Unit, Fondazione Policlinico Universitario A. Gemelli - Catholic University of the Sacred Heart, Rome, Italy

Background: Gastrointestinal (Gl) symptoms are seen in majority of patients with Systemic Sclerosis (SSc) and are a common presenting feature of disease. Severe Gl involvement may lead to malabsorption which represents a poor prognostic factor. Accordingly, a regular monitoring of gastrointestinal tract involvement and nutritional status appears crucial in SSc patients. Previous studies reported low values of bone mass density (BMD) in SSc patients ${ }^{1}$. While no specific relationship has emerged between the two conditions, it's likely that disease related $\mathrm{Gl}$ involvement may contribute to the alterations in BMD.

Objectives: To determine if Gl-related clinical status was associated to low bone density in our cohort of SSc patients.

Methods: Two-hundred-ten unselected SSc patients have been enrolled. The 7items UCLA SCTC GIT 2.0 questionnaire and Malnutrition Universal Screening Tool (MUST) were administered to each patient. A comprehensive medical history was collected. A blood panel for nutritional status was also performed. T-scores and Z-scores at lumbar spine, femoral neck, Ward's and total hip measured by dual-energy X-ray absorptiometry (GE Lunar Prodigy) were measured.

Results: In our cohort, $86.7 \%$ of patients reported some Gl symptoms. The mean UCLA GIT total score was $0.345 \pm 0.34$ and 51 patients $(24.3 \%)$ were at risk of malnutrition according to MUST (score $>1$ ). $53.7 \%$ patients had BMD values $<1$, and $12.5 \%$ had $\mathrm{BMD}$ values $\leq-2.5$ at any of the considered sections. Patients with reduced BMD $(<-1)$ showed similar levels of selected nutritional blood markers compared to subjects with normal BMD, including vitamin $\mathrm{D}$ and albumin.

Patients with spine T-score $<-1$ had lower BMI $(23.2 \pm 3.9$ vs $25.2 \pm 4.8$; $p=0.011)$ and reported higher UCLA GIT reflux $(0.66 \pm 0.63$ vs $0.42 \pm 0.48$; $p=0.016)$, distention $(0.80 \pm 0.72$ vs $0.53 \pm 0.56 ; p=0.15)$ and total score $(0.42+0.37$ vs $0.27 \pm 0.30$; $\mathrm{p}=0.006$ ) compared to patients with normal BMD. Similar significant differences were observed in the same domains for patients with total hip T-score values $<-1$. Femoral neck T-score $<-2.5$ was associated with higher UCLA GIT reflux $(0.88$ \pm 0.78 vs $0.48 \pm 0.50 ; p=0.022)$, soilage $(0.50 \pm 0.78$ vs $0.14 \pm 0.52 ; p=0.041)$ and total score $(0.50 \pm 0.37$ vs $0.31 \pm 0.33 ; p=0.012)$

On the other hand, the comparison of patients with severe, moderate and mild symptoms according to UCLA GIT total score ${ }^{2}$ showed an association between progressively lower values of spine and total hip T-score and increasing severity of Gl symptoms (ANOVA for spine T-score: $p=0.015$; for total hip T-score: $\mathrm{p}=0.048$ ).

Patients at risk of malnutrition (MUST score $\geq 1$ ) presented significant lower Tscore for all the considered sections (spine and hip) and significant lower total hip Z-score.

Conclusions: In our SSc cohort gastrointestinal symptoms were frequent and were associated with low BMD. Considering the heterogeneity of Gl involvement, UCLA SCTC GIT 2.0 emerged as a useful and feasible tool to assess GI involvement and other associated comorbidities. In particular, SSc patients who report remarkable GI symptoms and are at risk of malnutrition according to MUST may benefit from a stricter control of BMD to promptly detect osteopenia and osteoporosis.

\section{REFERENCES:}

[1] Omair MA, et al. J Rheumatol. 2013

[2] Khanna D, et al. Curr Opin Rheumatol. 2013

Disclosure of Interest: None declared

DOI: 10.1136/annrheumdis-2018-eular.7311

\section{AB0760 ADVANCED OXIDATION PROTEIN PRODUCTS IN SERUM OF PATIENTS WITH SYSTEMIC SCLEROSIS: A POSSIBLE INDICATOR OF CLINICAL EVOLUTION}

G. Sighinolfi, M. Colaci, A. Spinella, F. Lumetti, E. Artoni, C. Salvarani, D. Giuggioli. Chair and Rheumatology Unit, University of Modena and Reggio Emilia, Policlinico of Modena, Modena, Italy

Background: Systemic sclerosis (SSc) is a chronic, multisystem connective tissue disease characterised by by immune dys-regulation, obliterative microvasculopathy and fibrosis. Endothelial dysfunction, immune system imbalance and fibroblast activation constitute the three major factors of the pathogenetic process. In this context, oxidative stress could play a significant role through direct damage of endothelial cells and the persistent activation of the immune system. ${ }^{1,2}$
Objectives: This study investigated the presence of advanced protein oxidation products (AOPP) in serum of patients with SSc and its correlation with disease's features.

Methods: 50 patients with SSc (M:F 1:7, mean age 57.3 \pm 11.2 SD, mean duration of disease $10 \pm 9.1$ SD years), were screened for AOPP in the serum, using the AOPP OxiSelect Kit of CELL BIOLABS (San Diego, Ca, USA). Among $50 \mathrm{SSc}$ patients, 39 had limited cutaneous subset, while 11 had the diffuse one. Anamnestic and clinical data were collected for all SSc patients. As a control group 50 consecutive healthy subjects, sex and age matched, were recruited.

Results: We found serum levels of AOPP increased in the SSc group compared with the controls $(p<0.0001)$ with mean values of $336.9 \pm 167.8 \mathrm{mmol} / \mathrm{L}$ and 167.5 $\pm 59.2 \mathrm{mmol} / \mathrm{L}$, respectively. In addition, higher levels of AOPP directly correlated with the diffuse cutaneous subset $(p=0.0242)$, presence of digital ulcers $(p=0.005)$, esophagopathy $(p=0.006)$ and pulmonary fibrosis $(p=0.0128)$.

Conclusions: Serum AOPP levels are significantly higher in patients with SSc than in controls. In addition, the correlations of AOPP with SSc diffuse cutaneous subset, digital ulcers, and pulmonary involvement (indicative of progressive disease and worse prognosis) suggest a possible role of this marker in the identification of the cases with worse clinical evolution. The data of this preliminary study should be confirmed on larger case series and analysed in prospective studies, in order to understand its eventual usefulness during the follow-up of SSc patients.

\section{REFERENCES :}

[1] Ferri C, Valentini G, Cozzi F, Sebastiani M, Michelassi C, La Montagna G, et al. Systemic Sclerosis: Demographic, Clinical, and Serologic Features and Survival in 1,012 Italian Patients. Medicine (Baltimore). 2002; 81:139153

[2] Steen VD. The many faces of scleroderma. Rheum Dis Clin North Am 2008; 34:1-15

Disclosure of Interest: None declared

DOI: 10.1136/annrheumdis-2018-eular.6809

\section{AB0761 FOLLOW-UP OF NAILFOLD MICROVASCULAR DAMAGE IN MIXED CONNECTIVE TISSUE DISEASE VERSUS SYSTEMIC SCLEROSIS PATIENTS}

G. Ferrari, A. Sulli, C. Pizzorni, M. Ghio, M. Patanè, S. Paolino, A.C. Trombetta, M. Cutolo. Research Laboratory and Academic Division of Clinical Rheumatology, Department of Internal Medicine, University of Genova, San Martino Polyclinic Hospital, GENOA, Italy

Background: Nailfold videocapillaroscopy (NVC) is a non invasive diagnostic technique useful for evaluating microvascular status in patients with connective tissue diseases. ${ }^{1}$ In systemic sclerosis (SSc) capillary abnormalities, when evaluated by NVC, evolve in a clearly defined sequence called the "scleroderma patterns" (Early, Active, Late). ${ }^{2}$ On the contrary, mixed connective tissue disease (MCTD) doesn't show characteristic either nailfold capillary abnormalities or typical sequence. ${ }^{1,2}$ Until today, few studies described the main NVC changes in MCTD. ${ }^{3}$

Objectives: To retrospectively study nailfold microangiopathy by NVC in MCTD patients with a follow-up of three years and to compare capillaries abnormalities between patients affected by MCTD and SSc.

Methods: Ten patients (mean age $50 \pm 19$ years) affected by MCTD with Raynaud phenomenon (Kasukawa's criteria) ${ }^{4}$ who performed their first NVC were enrolled. Among these, complete capillaroscopic and clinical data at three years were available for 7 patients (disease duration $6.4 \pm 4.2$ years). Main NVC parameters (absolute number of normal and total capillaries and scores of capillary ramifications, enlarged capillaries, giant capillaries, microhemorrhages, number of capillaries) were evaluated by NVC at baseline (T0, first NVC), and after one (T1) and three years (T3). Possible variations of capillary findings were analysed, along with correlations among capillaroscopic and clinical parameters. Furthermore, we compared main NVC parameters at TO of ten above-mentioned MCTD patients versus ten random SSc patients with the same disease duration (6.4 44.2 years) and similar age ( $51 \pm 17$ years). Statistical analysis was performed by non parametric tests. The patients were receiving different immunosuppressive treatments.

Results: No statistically significant variation of the scores as well as of the absolute value of the above reported capillary parameters was observed during the 3 years of follow-up. No statistically significant correlation was observed between capillary parameters and MCTD clinical aspects (Raynaud phenomenon, dysphagia, dyspnoea, sclerodactily, sicca syndrome, telangiectasies and arthralgia) at first visit and during follow-up. The scores of enlarged capillaries and giant capillaries were found significantly higher $(p<0.05)$ in patients with SSc versus MCTD patients at T0. Moreover, the absolute number of total capillaries and normal capillaries were found significantly lower $(p<0.05)$ in SSc patients versus MCTD patients. On the contrary, no statistically significant difference was observed for 
the other capillary parameters (capillary ramification, microhemorrhages) between the two groups of patients.

Conclusions: In a limited cohort of MCTD patients with an average disease duration of 6.4 years and a follow-up of three years, the nailfold microangiopathy does not seem to be significantly progressive. Patients with MCTD seem to show less enlarged/giant capillaries, and larger absolute number of total and normal capillaries than SSc patients. Still difficult to identify a defined NVC pattern in MCTD patients.

\section{REFERENCES:}

[1] Cutolo M. et al. Best Pract Res Clin Rheumatol 2008; 22:1093-108.

[2] Cutolo M. et al. J Rheumatol. 2000; 27:155-60.

[3] De Holanda Mafaldo DA, et al. Lupus. 2007; 16:254-8.

[4] Cappelli S. et al. Semin Arthritis Rheum. 2012; 41:589-98.

Disclosure of Interest: None declared

DOI: 10.1136/annrheumdis-2018-eular.5539

\section{AB0762 RELATIONSHIP OF THE SIX MINUTE WALKING TEST AND QUALITY OF LIFE IN PATIENTS WITH SYSTEMIC SCLEROSIS}

G. Cuomo, K. GJELOSHI, F. Masini, F. Danzo, C. Romano, L.E. Adinolfi. UOC Medicina Interna, UNIVERSITA DEGLI STUDI DELLA CAMPANIA, NAPOLI, Italy

Background: The six minute walking test $(6 \mathrm{MWT})$ is a standardised measure of submaximal exercise capacity. It is a surrogate measure of heart and lung involvement. There are no studies on relationship between 6MWT and quality of life evaluated by Short form 36 .

Objectives: To evaluate the relationships between of the 6 min walking distance (6MWD) and each items of SF36

Methods: Fifty consecutive SSc patients were investigated. They underwent 6MWT and complete the SF-36 (assessed the 8 domains of the questionnaire as well as the physical component score-PCS and mental component score-MCS).

Results: 6MWD ranged from 253 to 582 (median 420); we listed the correlations from 6MWT and only the statistically significant features of SSc and the items of SF36

Age: median 48 (range 20-72); Rho $-0.51 ; \mathrm{p}<0.00001$

EScSG Activity Index: median 0.5 (range 0-5); Rho -0.33; p0.009

HAQ-DI: median 0.375 (range 0-2.275); Rho -0.26; p 0.048

mRSS: median 2 (range 0-17); Rho-0.35; p0.007

Pulmonary hypertension (echocardiography): median 30 (range 13-80); Rho $-0.26 ; p 0.048$

SF36: PCS: median 43 (range 20-65); Rho 0.41; p 0.0016

PF: median 75 (Range 0-100); Rho 0.40; p 0.002

$\mathrm{GH}$ : median 50 (range 10-92); Rho 0.43; p 0.0007

Conclusions: Our study first demonstrates that 6MWT is correlated to some aspects of quality of life as measured by SF36 in the SSc patients. This results must been considered when assessing 6MWT in SSc.

\section{REFERENCES:}

[1] Schoindre $Y$ et al, J Rheumatol 2009.

[2] Flaherty et al, Am J Respir Crit Care Med 2006

[3] Casanova C. et al, Eur respire J 2007

Disclosure of Interest: None declared

DOI: 10.1136/annrheumdis-2018-eular.4315

\section{AB0763 BIOELECTRICAL IMPEDANCE ANALYSISFOR THE ASSESSMENT OF BODY COMPOSITION IN PATIENTS WITH SYSTEMIC SCLEROSIS}

G. Cuomo, G. Guarino, F. Danzo, C. Romano, F. Masini, R. Ferrara, S. Gentile, L. E. Adinolfi. UOC Medicina Interna, UNIVERSITA DEGLI STUDI DELLA CAMPANIA, NAPOLI, Italy

Objectives: The aim of the present study was to evaluate the body composition by bioelectrical impedance analysis (BIA) and to assess the nutritional status by $\mathrm{BMI}$ and possible correlations with epidemiological and clinical characteristics in patients with SSc

Methods: Malnutrition was defined as $\mathrm{BMI}<18.5 \mathrm{~kg} / \mathrm{m} 2$ or unintentional weight loss $>10 \%$ in combination with a fat-free mass index (FFMl) $<15 \mathrm{~kg} / \mathrm{m} 2$ for women or $<17 \mathrm{~kg} / \mathrm{m} 2$ for men or $\mathrm{BMl}<20.0 \mathrm{~kg} / \mathrm{m} 2$ (age $<70$ years) or $<22 \mathrm{~kg} / \mathrm{m} 2$ (age $>70$ years). Body composition was assessed in 40 patients (female) (age mean \pm sd: $45.2 \pm 12.2$ ) and 20 healthy controls (age mean \pm sd $41.5 \pm 5.3$ ) with BIA
(Akern, Italy) and BMI. The manufacturer's equation and the Geneva equation were used to estimate fat mass (FFM).

In addition, correlations with disease activity, gastrointestinal severity, disease subset, autoantibody profile, skin score were evaluated.

Results: Malnutrition was found in $10 \%$ of patients vs $8 \%$ of healty controls; and low FFMI in $30 \%$ of patients vs 105 of $\mathrm{HC}$. Bioimpedentiometry showed a Fat Free Mass (FFM) (metabolically active component of fat free mass) reduced in patients compared to controls $(46.8 \pm 7.6$ vs $53.6 \pm 6.3$ respectively; $p=0.01)$. Fur thermore, with the same instrument a lower basal metabolic rate was found in patients compared to controls: $1462 \pm 145$ vs $1720 \pm 169$ calories $(p=0.001)$. The correlations between FFM and basal metabolism with the clinical features of the patients were not statistically significant

Conclusions: This study confrim the study of Spanjer $\mathrm{MJ}$ et $\mathrm{al}^{1}$ and shows a relatively low prevalence of malnutrition in comparison with other studies, but a high prevalence of low FFMI, underlining the necessity of measuring body composition in SSc patients with a standardised and validated method. Furthermore, Caporali et $a l,{ }^{2}$ have shown an alteration of the nutritional status of patients of SSc probably related to a gastro-intestinal commitment. In our patients despite the presence of an apparent good nutritional status the use of bioimpedanceometry revealed a dif ferent body composition, a lower share of muscle mass, in patients compared to controls, related, in part, to musculoskeletal involvement by systemic sclerosis (increase in muscle catabolism and/or poor nutrient supply due to malabsorption phenomena). The early detection of such alterations could be useful to insert subjects at risk in physical rehabilitation programs.

\section{REFERENCES}

[1] Spanjer MJ et al, Rheumatology 2017

[2] Caporali et al; Clin Nutr 2012

Disclosure of Interest: None declared DOI: 10.1136/annrheumdis-2018-eular.4298

\section{AB0764 COMPARISON OF DISEASE CHARACTERISTICS IN PATIENTS WITH JUVENILE-ONSET AND ADULT-ONSET PROGRESSIVE SYSTEMIC SCLEROSIS}

G. Karatemiz ${ }^{1}$, A. Androvic ${ }^{2}$, S.N. Esatoglu ${ }^{1}$, S. Sahin ${ }^{2}$, K. Barut ${ }^{2}$, G. Hatemi ${ }^{1}$, V. Hamuryudan ${ }^{1}$, O. Kasapcopur ${ }^{2}$, E. Seyahi ${ }^{1} .{ }^{1}$ Rheumatology, ${ }^{2}$ Pediatric Rheumatology, Istanbul University of Cerrahpasa Medical Faculty, Istanbul, Turkey

Background: Progressive systemic sclerosis (PSSc) has been known to affect mainly adults of 30-50 years of age. Juvenile -onset has been reported to be rare and studies comparing clinical differences between juvenile-onset and adult onset form have been limited. ${ }^{1}$ These studies were coming from European and North American countries. ${ }^{1-2}$ As there would be also effects of ethnic differences, we aimed to assess clinical differences between the two forms of pSSc of paediatric and adult rheumatology centres of a tertiary centre, in Turkey.

Methods: Adult onset patients were defined as those who were registered and followed as 'scleroderma' at the departments of adult and paediatric rheumatology at Cerrahpasa Medical Faculty, Istanbul, between 2005 and 2017. Only those with at least 2 follow-up visits were included. Patients's charts were re-evaluated retrospectively.

Abstract AB0764 - Table 1

\begin{tabular}{lccc}
\hline & $\begin{array}{c}\text { Adult onset, } \\
\mathrm{n}=137\end{array}$ & $\begin{array}{c}\text { Juvenile onset, } \\
\mathrm{n}=26\end{array}$ & $\mathrm{P}$ \\
\hline Age at disease onset, mean \pm SD & $38.6 \pm 13.4$ & $10.1 \pm 4.3$ & - \\
Age at diagnosis, mean \pm SD & $43.6 \pm 14.0$ & $11.4 \pm 3.2$ & - \\
Follow-up duration, med. [IQR], years & $5[2.0-7.0]$ & $4[2.5-6.0]$ & $\mathrm{NS}$ \\
Male/Female & $20 / 117$ & $2 / 24$ & $\mathrm{NS}$ \\
Familial history of chronic inflammatory & $20(14.6)$ & $4(15.4)$ & $\mathrm{NS}$ \\
diseases, $\mathrm{n}(\%)$ & & & \\
Sclerodactyly, $\mathrm{n}(\%)$ & $128(93.4)$ & $25(96.2)$ & $\mathrm{NS}$ \\
Raynaud phenomenon, $\mathrm{n}(\%)$ & $135(98.5)$ & $24(92.3)$ & $\mathrm{NS}$ \\
Digital ulcers, $\mathrm{n}(\%)$ & $55(41.4)$ & $14(54.0)$ & 0.001 \\
Interstitial lung disease, $\mathrm{n}(\%)$ & $71(52.2)$ & $6(24.0)$ & 0.009 \\
PAH, $\mathrm{n}(\%)$ & $20(14.9)$ & 0 & 0.045 \\
Arrhythmia/heart failure, $\mathrm{n}(\%)$ & $14(10.4)$ & $1(4.0)$ & $\mathrm{NS}$ \\
Joint involvement, $\mathrm{n}(\%)$ & $20(14.9)$ & $13(50.0)$ & $<0.001$ \\
Skleletal muscle involvement/myopathy $\mathrm{n}(\%)$ & $10(7.5)$ & $7(28.0)$ & 0.002 \\
Gastrointestinal system involvement, $\mathrm{n}(\%)$ & $42(31.8)$ & $8(32.0)$ & $\mathrm{NS}$ \\
Arterial hypertension, $\mathrm{n}(\%)$ & $24(18.2)$ & 0 & 0.015 \\
ANA positivity, $\mathrm{n}(\%)$ & $119(93.0)$ & $18(75.0)$ & 0.007 \\
DMARD use, $\mathrm{n}(\%)$ & $90(65.7)$ & $25(96.2)$ & 0.002 \\
Vasodilators, $\mathrm{n}(\%)$ & $113(82.5)$ & $13(50.0)$ & $<0.001$ \\
\hline
\end{tabular}

Results: There were 140 patients with scleroderma in the adult outpatient clinic records and 51 in the paediatric clinic records. Of these patients, $3(2 \%)$ adults 